\title{
Risk Evaluation in Manufacturing Organization Tasks for Product Technological Projects and Establishment of Project Portfolio for Production Systems
}

\author{
Leonid Mylnikov* \\ Perm National Research Polytechnic University, 29 Komsomolsky Prospekt, Perm, Russia \\ *Corresponding author
}

\begin{abstract}
This paper broadly outlines the task of evaluating the risks associated with planning when tackling the issues of choice and planning in productive-and-economic systems to implement the projects resulting from the application of criteria-based approaches, as well as the task of evaluating production risks.
\end{abstract}

Keywords-manufacturing planning; risk evaluation; simulation modeling; innovation project; productive-and-economic system

\section{INTRODUCTION}

Currently, organization and structure of traditional production are changing rapidly. The marginality of production systems is decreasing. Now, the main share of profits is accounted for product planners. In these circumstances, the planners, on the one hand, look for production systems which, to the greatest extent possible, meet their requirements, while the production systems, on the other hand, become increasingly active economic agents that effectively address the challenges of searching and acquiring technologies and projects, optimizing portfolio of products and output volumes, etc. In this connection methods and techniques of formalization and solution of product portfolio tasks, their risk optimization and search for production systems for product innovation take a significant role.

A large number of existing formalization techniques of such tasks has certain shortcomings. However, among scientists working on this theme, there is a large number of Nobel Laureates (L. Kantorovich, 1975; J. Clark, 1987; H. Markowitz, 1994; J. Stiglitz, 2001; J. Tirole, 2014). V.N. Arkhangelsky emphasizes the crucial role of management and significance of the higher degree of formalization of management principles and their applicability within the existing approaches and concepts.

The task of product management was initially viewed by A. Calmes as a problem of records and statistics in the manufacture and commodity production [1]. The task outgrew into the development of planning methods (refer to the works of F. Taylor [2] and H. Gantt [3]). Further development of science in this field was related to the improvement of mathematical formalization methods (which began with such scientists as J. von Neumann [4], L. Kantorovich), as well as to consideration of as many factors as possible, on one side, and to preparation and elaboration of managerial decisions within the entire manufacturing fields (for instant, in the works of J. Tirole in the field of management on the industry markets (refer to [5], for example)), on the other side, as an attempt to describe "the physics" of the processes occurring in productive-and-economic systems which resulted in the theory of operational functions (J. Clark and R. Solow [6]).

\section{MATHEMATICAL FormaLIZATION OF MANAGEMENT TASKS}

In spite of all its advantages, the task of mathematical formalization which is generally related to the market selection and manufacturing planning is unsolvable (especially in cases where a multitude of criteria is considered). The research literature has already shown that this task is NPcomplete (for example, refer to [7]).

In practice, therefore, resolving such tasks means achieving a set of goals based on structure modeling [8]. Let us consider some examples of such tasks:

A. Model 1. Master Production Scheduling for Product Groups Based on the Forecasting of Demand and Market Saturation

$$
\begin{gathered}
\sum_{v=1}^{u}\left(Q_{v \bar{v}}(t)-\sum_{g=1}^{\left.h_{h_{v}} z_{v \bar{g}}(t)\right) X_{v}(t) \rightarrow m \tau n},\right. \\
\sum_{v} \Sigma_{g} R_{g v} X_{v}(t) \leq P \\
\Sigma_{v} \Sigma_{t} S_{g v} X_{v}(t) \leq T \\
X_{v}(t) \leq G_{v}(t)
\end{gathered}
$$

where $X_{v}$ - output of $v$ product, $Q_{v b}-$ selling price of $v$ product manufactured in $b$ productive-and-economic system, $z_{w b g}$ - cost of $g$ operation performed in $b$ productive-andeconomic system when manufacturing $v$ product, where $R_{g v}$ required capacity of each type of equipment per one finished product, $s_{g v}$ - required key materials per one finished product, $G_{v}$ - market limitation for $v$ product (is determined on the basis of sales volume of the product or its analogue), $P$ - total capacity resource for each type of equipment calculated at the average efficiency of all equipment of that type; and $T$ - volume of available key materials determined on the basis of information on status of stock and procurement plan. 
B. Model 2. Selection of Approach and Production Systems for Implementation of New Innovation Projects

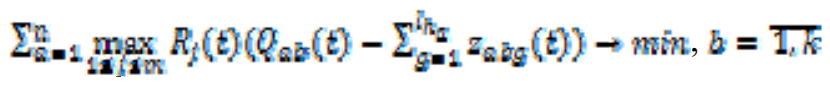

$$
\begin{aligned}
& \Sigma_{v} \Sigma_{g} R_{g v} X_{v}(t) \subseteq P, \\
& \Sigma_{v} \Sigma_{t} S_{g v} X_{v}(t) \leq T .
\end{aligned}
$$

where $R_{j}$ is market capacity $j$.

\section{RISKS EVALUATION}

Over-time consideration of parameters makes it possible to care for risks associated with the choice of innovation projects (managerial and organizational), for which membership function may be identified for every moment of time.

In this case, the expected return of product portfolio may be determined as is evident from [9]:

$$
E\left(R_{p}\right)=\sum_{v-1}^{u} x_{v} E\left(R_{v}\right),
$$

where $R_{p}$-product portfolio, and $x_{i}$ - output volume.

To evaluate the risk of project portfolio we shall use CAPM (Capital-Asset-Pricing-Model) which is suggested by W. Sharpe [10], J. Lintner [11], and J. Mossin [12], and is based on H. Markowitz's theory described in [13] and [14]:

$$
\operatorname{VAR}\left(R_{p}\right)=\Sigma_{l=1} \Sigma_{j=1}^{l} x_{l} x_{j} \operatorname{COV}\left(R_{j}, R_{i}\right)
$$

Correlation factor can be calculated by the formula:

$$
\kappa_{t j}=\frac{\operatorname{cov}\left(N_{g} N_{L}\right)}{\sigma_{b} \sigma_{j}}
$$

Then the risk evaluation for $p$ project portfolio is:

\begin{tabular}{|c|c|c|c|c|c|c|}
\hline 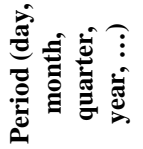 & 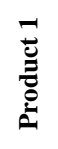 & 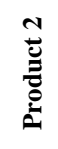 & $\cdots$ & $\begin{array}{l}a \\
\stackrel{a}{\Xi} \\
\stackrel{a}{0}\end{array}$ & $\cdots$ & 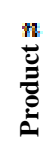 \\
\hline 1 & $O_{11}$ & $a_{n 1}$ & $\ldots$ & $a_{=1}$ & $\ldots$ & $o_{n 1}$ \\
\hline$!$ & $i$ & 1 & & 1 & & 1 \\
\hline$N$ & $o_{2 n}$ & $a_{n}$ & $\cdots$ & $O_{a v}$ & $\ldots$ & $o_{n N}$ \\
\hline
\end{tabular}

$$
\sigma_{p}=\sqrt{\sum_{l=1}^{l} \Sigma_{j-1}^{l} x_{l} x_{j} k_{q} \sigma_{l} \sigma_{j}}
$$

When statistical data is available (Table 1), the correlation factor can be determined with the use of SlopeOne family algorithm[15].

\section{TABLE I. SALES VOLUME MATRIX}

where $w-$ number of period under review, $\boldsymbol{q}_{j}$ - sales volume over period of time.
In this case, the angle cosine between vectors formed by columns of values for each product (item-to-item algorithm) can be used as the correlation factor:

$$
S=\cos \left(T_{1}, T_{2}\right)=\frac{\tau_{1} \tau_{2}}{\left|\tau_{1}\right|\left|F_{2}\right|}
$$

where $T$ - vectors (columns) corresponding to products.

These calculations can be subsequently used to fill in the product correspondence table (refer to Table 2):

\section{TABLE II. PRODUCT CORRESPONDENCE (SALES VOLUME CORRELATION)}

\begin{tabular}{|c|c|c|c|c|}
\hline & Product 1 & Product 2 & $\ldots$ & Product $\boldsymbol{n}$ \\
\hline Product 1 & 1 & $S_{\mathrm{nz}}$ & $\ldots$ & $S_{2 \pi}$ \\
\hline Product 2 & $S_{\mathrm{nI}}$ & 1 & $\ldots$ & $S_{\mathrm{n}}$ \\
\hline$\vdots$ & $\vdots$ & $\vdots$ & $\ddots$ & $\vdots$ \\
\hline Product $\boldsymbol{n}$ & $S_{\mathrm{n}}$ & $S_{n \pi}$ & $\ldots$ & 1 \\
\hline
\end{tabular}

In this case, portfolio will be chosen on the assumption that the expected return can be also determined by the following formula [9]:

$$
E\left(R_{p}\right)=R_{f}+\frac{\sigma\left[R_{m}\right)-R_{f}}{\theta_{m}} \sigma_{p}
$$

where $R_{f}$ - guaranteed risk-free return, $E\left(R_{\eta}\right)$ - expected return of pportfolio, $E\left(R_{m}\right)$ - expected return of $m$ market the portfolio, $\sigma_{p}$ - standard deviation for $p$ portfolio, and $\sigma_{m}$ standard deviation for $m$ portfolio.

\section{Risk Evaluation When Using Forecasting Data}

Parameters of innovation projects change their values as innovation-, S- curves and etc. There are methods which use for forecasting of projects` parameters (see $[16,17]$ ).

For data obtained from forecasts $\mu=\int_{-\infty}^{+\infty} x f(x) d x$, a

$$
\sigma^{2}=\int_{-\infty}^{+\infty}(x-\psi)^{2} f(x) d x
$$

where $x$-product output at the point of time being evaluated.

For historical data:

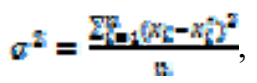

where $x_{i}-$ actual output at the point of time being evaluated, and $x_{i}^{*}$ - forecasted output at the point of time being evaluated.

In the second case, the resulting value will depend on the numerical value of the parameter being evaluated, and its use together with results of other assessments may involve the following approach.

Let's assume that $r$ risk factor is calculated for a certain set of project parameters taking into account all the factors affecting this risk, i.e. the risk factor is considered a function of many variables:

$$
r=r\left(a_{1}, a_{2}, \ldots, a_{R_{2}}, \varphi_{1}, \varphi_{2}, \ldots, \varphi_{n}\right)
$$


where, supposedly, $a_{1}-$ product unit cost (cost-per-unit), $a_{2}-$ product unit price, $a_{2}-$ sales volume, etc. In this case, when the risk factor is calculated for the first parameter, then $\eta_{1}$ is a function of the following factors: $\phi_{1}-$ decline in output (interruptions in supplies of primary products, materials and/or components, bad quality of products due to a fault of personnel and/or due to malfunction of equipment, deliveries of defective primary products, materials and/or components, accidents, natural disasters, strikes and/or wars); $\phi_{2}$ - growth of output; $\varphi_{3}$-changes in the prices for primary products, materials and/or components; $\varphi_{4}$ - changes in the cost of labor; $\varphi_{5}$ - changes in the prices for packing, storage, transport, merchandizing and other services of third-party organizations; $w_{5}$ - tax services; $\varphi_{7}$ - occurrence of inflationary or deflationary processes; $\varphi_{g}$ - shortage of liquid funds which causes borrowing and payment of interest thereon; and $p_{9}$ - fines, penalties and forfeits, paid.

As a rule, the approach of expert adjustment of the risk factor in the light of affecting factors is used.

To ensure certainty, let us assume that the risk factor is calculated in the light of particular number of affecting factors:

$$
r=1-a_{k} s
$$

where $a$ - fixed and planned product unit cost, regardless of the risk factor; and $a^{*}$ - adjusted product unit cost.

The adjusted risk factor used in this formula must be determined at least by two experts, where one of the experts may calculate it in the light of four factors affecting the cost, while another may take account of nine factors, for instance.

The range of values of the parameter of interest (which is to say that the risk factor calculated through this method will definitely be within this range that establishes a fuzzy set, accordingly) is determined on the basis of the expert estimates.

The membership function is also determined on the basis of the expert estimates depending on the possibility of risk events which affects each value. Then the risk factor is calculated:

$$
\eta_{1}=\frac{\int_{\alpha}^{\beta} x \mu(x) d x}{\int_{\alpha}^{\beta} \mu(x) d x}
$$

where $r$ - risk factor; $\beta(x)$ - membership function; $\alpha, \beta-$ value rang limits.

The proposed method is also applicable when the value of any parameter of the innovation project is used as the risk factor.

Let us suppose that the value of $r_{0}$ risk factor corresponds to the value of $a_{1}$ parameter (product unit cost). The cost value at this point will most likely correspond to the actual value at zero level of impact of risk events relating to the parameter under consideration, which means that such events will neither happen nor have any impact on the result. Then we are to determine the value of risk factors that could have either negative (loss of a part of resources, loss or nonacquisition of income, or additional expenses) or positive (increase in profits, reduced expenses or other benefits) result.

This value will be expressed as a right or left deviation from $r_{0}$, after which the range of a fuzzy set of the $a_{1}$ parameter will be established. This set membership function will be determined for each value within this range (when the membership degree of $\eta_{0}$ risk factor value will be equal to 1 ). Then the values of the risk factor will be averaged by the formula based on these functions.

\section{RISKS OF ECONOMIC ACTIVITIES}

In addition to the risks associated with product planning productive-and-economic systems may have risks related to economic activities: technical risks, project implementation risks, qualitative risks, etc. These risks can be considered in the decision sensitivity analysis by means of the Monte Carlo method which invites the use of simulation modeling, namely, mathematical modeling of possible malfunctions of equipment, deliveries of materials, direct change in output due to defective products or failure to ship the products, etc. In this case, the companies working for open markets will just move on the yield curve, and their risk will be associated with the failure to fulfill internal liabilities and, in some cases, liabilities towards other companies within the production chain, and the companies having stringent term contracts for supply will face higher risks connected with penalties.

Considering the task of selecting productive-and-economic system for the project involves evaluation of planning risks just for one project, whereas the risks of economic activities also have a significant role. Since it is difficult to evaluate such risks without the relevant experience, their minimization will be limited to the diversification of production systems and creation of a line of products for several markets.

Thus, the main task is to consider many products for many productive-and-economic systems.

\section{CONCLUSION}

The introduction of additional time factor in risk planning and evaluation as distinct from the model of $\mathrm{H}$. Markowitz makes it possible to take into account managerial and organizational risks which are generalized for groups of projects, other than deterministic risks, and, in general, does not impose any restrictions on markets unlike the works of J. Tirole who has resolved the problem of product portfolio selection on industry markets.

The use of step-to-step transition points of projected parameters or points connected with production cycles as decision points gives us an opportunity to escape the problem of infinite horizon [18] and to avoid such phenomenon as an innovation regression in productive-and-economic systems.

\section{ACKNOWLEDGMENT}

The author thanks the government of Perm Krai for the support of the project for "Development of software and economic and mathematical models for supporting innovation project management processes in production systems", which 
is being implemented in accordance with decree No. 166-ח of 06.04.2011.

The reported study was partially supported by the Government of Perm Krai, research project No. C-26/058.

\section{REFERENCES}

[1] K.-I. Voigt, Industrielles Management: Industriebetriebslehre aus prozessorientierter Sicht. Berlin: Springer, 2008.

[2] F.W. Taylor, The principles of scientific management. New York, NY: Norton, 1967.

[3] H.L. Gantt and D. Forrer, Organizing for work/ by Henry Laurence Gantt; edited and introduction by Donald A. Forrer. Florida: Dr, Donald A. Forrer, 2006

[4] J. Von Neumann and O. Morgenstern, Theory of games and economic behavior, 60th anniversary ed. Princeton, N.J.; Woodstock: Princeton University Press, 2007.

[5] P. Joskow and J. Tirole, "Reliability and competitive electricity markets" RAND J. Econ., vol. 38, no. 1, pp. 60-84, Mar. 2007.

[6] R.M. Solow, "Technical Change and the Aggregate Production Function” Rev. Econ. Stat., vol. 39, no. 3, p. 312, Aug. 1957.

[7] W. Van den Heuvel, O.E. Kundakcioglu, J. Geunes, H.E. Romeijn, T.C. Sharkey and A.P.M. Wagelmans, "Integrated market selection and production planning: complexity and solution approaches" Math. Program., vol. 134, no. 2, pp. 395-424, Sep. 2012.

[8] L. Mylnikov, "Conceptual Foundations of Modelling of Innovative Production Projects" Proc. Int. Conf. Appl. Innov. IT, no. 3, pp. 13-17, 2015.

[9] U. Vanini, Risikomanagement: Grundlagen, Instrumente, Unternehmenspraxis. Stuttgart: Schäffer-Poeschel, 2012.

[10] W.F. Sharpe, "Capital Asset Prices: A Theory of Market Equilibrium under Conditions of Risk" J. Finance, vol. 19, no. 3, p. 425, Sep. 1964.

[11] J. Lintner, "The Valuation of Risk Assets and the Selection of Risky Investments in Stock Portfolios and Capital Budgets" Rev. Econ. Stat., vol. 47, no. 1, p. 13, Feb. 1965.

[12] J. Mossin, "Equilibrium in a Capital Asset Market" Econometrica, vol. 34, no. 4, p. 768, Oct. 1966.

[13] H. Markowitz, "Portfolio Selection” J. Finance, vol. 7, no. 1, p. 77, Mar. 1952.

[14] H.M. Markowitz, Portfolio selection: efficient diversification of investments, 2. printing. New Haven, Conn.: Yale Univ. Press, 1970.

[15] D. Lemire and A. Maclachlan, "Slope One Predictors for Online RatingBased Collaborative Filtering" SIAM Data Min. SDM05 Newport Beach Calif. April 21-23, 2005.

[16] M. Amberg, L. Mylnikov "Innovation project lifecycle prolongation method", Innovation and Knowledge Management in Twin Track Economies: Challenges \& Solutions, no. (1-3), pp. 491-495, 2009.

[17] L. Mylnikov, M. Amberg, "The Forecasting of Innovation Projects Parameters", 21st International-Business-Information-ManagementAssociation Conference on Vision 2020: Innovation, Development Sustainability, and Economic Growth, no. 1-3, pp. 1017-1029, 2013.

[18] A. Paprotny and M. Thess, Realtime data mining: self-learning techniques for recommendation engines, 2013. 